University of Wollongong

Research Online

Faculty of Informatics - Papers (Archive)

Faculty of Engineering and Information

Sciences

$11-7-2005$

\title{
The pros and cons of RFID in supply chain management
}

Katina Michael

University of Wollongong, katina@uow.edu.au

Luke McCathie

University of Wollongong, lukemccathie@gmail.com

Follow this and additional works at: https://ro.uow.edu.au/infopapers

Part of the Physical Sciences and Mathematics Commons

\section{Recommended Citation}

Michael, Katina and McCathie, Luke: The pros and cons of RFID in supply chain management 2005.

https://ro.uow.edu.au/infopapers/105

Research Online is the open access institutional repository for the University of Wollongong. For further information contact the UOW Library: research-pubs@uow.edu.au 


\title{
The pros and cons of RFID in supply chain management
}

\author{
Abstract \\ This paper presents the pros and cons of using radio-frequency identification (RFID) in supply chain \\ management (SCM). While RFID has a greater number of benefits than its predecessor, the bar code, it \\ currently comes at a price that many businesses still consider prohibitive. On the one hand, RFID is \\ advantageous because it does not require line-of-sight scanning, it acts to reduce labor levels, enhances \\ visibility, and improves inventory management. On the other hand, RFID is presently a costly solution, \\ lacking standardization, it has a small number of suppliers developing end-to-end solutions, suffers from \\ some adverse deployment issues, and is clouded by privacy concerns. Irrespective of these factors, the \\ ultimate aim of RFID in SCM is to see the establishment of item-level tracking which should act to \\ revolutionize SCM practices, introducing another level of efficiencies never before seen.

\section{Disciplines} \\ Physical Sciences and Mathematics

\section{Publication Details} \\ This article was published as: Michael, K, \& McCathie, L, The pros and cons of RFID in supply chain \\ management, Proceedings of the International Conference on Mobile Business, 11-13 July 2005, 623-629. \\ Copyright IEEE 2005.
}




\title{
The Pros and Cons of RFID in Supply Chain Management
}

\author{
Katina Michael, Luke McCathie \\ University of Wollongong \\ katina@uow.edu.au,lukemccathie@gmail.com
}

\begin{abstract}
This paper presents the pros and cons of using Radio-Frequency IDentification (RFID) in Supply Chain Management (SCM). While RFID has a greater number of benefits than its predecessor, the bar code, it currently comes at a price that many businesses still consider prohibitive. On the one hand, RFID is advantageous because it does not require line-of-sight scanning, it acts to reduce labor levels, enhances visibility, and improves inventory management. On the other hand, RFID is presently a costly solution, lacking standardization, it has a small number of suppliers developing end-to-end solutions, suffers from some adverse deployment issues, and is clouded by privacy concerns. Irrespective of these factors, the ultimate aim of RFID in SCM is to see the establishment of item-level tracking which should act to revolutionize SCM practices, introducing another level of efficiencies never before seen.
\end{abstract}

\section{Introduction}

Supply Chain Management (SCM) is the "management and control of all materials and information in the logistics process from acquisition of raw materials to delivery to the end user" [1]. Nine out of ten companies rate SCM and stock control as the key to their company's future success, even survival [2]. Radio Frequency IDentification (RFID) technology has opened the door to a new era in SCM, unachievable using existing barcode technology. Leading corporations have recognized the intrinsic advantages of RFID and recently moved to introduce the technology in SCM by establishing a mandate, forcing suppliers to use RFID as well. There is still reluctance in the business community to invest large amounts of capital in such new technology that is yet to prove itself. Compounding this reluctance is the fact that many of these businesses have invested heavily in legacy barcode systems. There is a preference to use a cautious approach, waiting to see what global business leaders do. For this reason, this paper is strategic in informing the business community of the pros and cons of adopting RFID technology for SCM.

\section{Methodology}

The primary method of data collection involved qualitative content analysis. Given that RFID is an emerging technology, reliance for literature was based on a wide range of online industry sources, including RFID vendor web sites, standards organizations, whitepapers and press releases. The online sources were complemented by hardcopy documentation including books and academic papers. The relevant material was gathered, categorized and sorted into like themes which formed the basis for the advantages and disadvantages of RFID in supply chain management. Two semi-structured interviews were also used to supplement and further validate the findings of the content analysis. Participant 1 was an employee of a leading auto-ID company, and Participant 2 was an end-user of RFID in one of the world's largest oil refineries. This paper is both descriptive and interpretive.

\section{Non-Line-of-Sight Technology}

\subsection{Automatic Non-Line-of-Sight Scanning}

One of RFID's most attractive offerings is its fundamental attribute of not requiring line-of-sight when reading RFID tags. This means items do not require particular orientation for scanning, unlike barcodes. This inbuilt technological characteristic acts as an enabler leading to a plethora of advantages at numerous levels throughout the supply chain. RFID scanners can communicate to tags in milliseconds and have the ability to scan multiple items simultaneously. This ability significantly aids the automation of many SCM tasks that have typically been labor intensive 
roles such as checking and scanning incoming inventory. Organizations also have an accurate picture of stock levels which in turn means lower inventory costs and less out-of-stock occurrences.

\subsection{Labor Reduction}

RFID promises to help automate the supply chain to unprecedented levels, leading to labor reduction throughout the process. The major cost component for typical distribution centers is labor, accounting for around $50-80 \%$ of their total distribution costs. Keith et al., predict that receiving check-in time could be reduced by $60-93 \%$ with RFID technology [3]. It is also estimated that RFID could yield labor savings of up to $36 \%$ in order picking and a $90 \%$ reduction in verification costs for shipping processes. These figures demonstrate the significance of labor in supply chains and that even small reductions can deliver considerable financial savings. For example, prior to Collex's RFID implementation, drivers had to get out of their trucks at landfills, manually enter their waste details and wait for a ticket [4]. Drivers were also required to wait for a ticket when leaving the landfill; in all a time consuming process. When truck drivers now enter a landfill, they merely have to stop on the weighbridge, hold their RFID tag next to the reader and wait a second for their printed ticket. Retailers in particular, stand poised to benefit from RFID, as they can remove the large labor component required to manage stock in their stores. Furthermore, RFID ultimately promises the inception of instantaneous operator free checkouts.

\subsection{Enhanced Visibility}

The pervasive 'always-on' nature of RFID technology equates to greater visibility to all stakeholders in the supply chain. It is estimated that the U.S. retail industry is losing about US\$70 billion annually from its SCM practices [5]. About $42 \%$ of this comes from product not being on the retail shelf for consumers, with the remainder derived through losses within the supply chain. The visibility offered by RFID could help to reduce this loss, by reducing waste, lowering inventory levels and improving safety. Improving visibility in the supply chain can help "lower distribution and handling costs and reduce inventory levels" [6]. RFID allows products to be followed in real-time across the supply chain providing accurate and detailed information on all items, allowing organizations to use this information to increase efficiency. Inventory visibility can be used to achieve gains in areas such as faster response to customer demands and market trends, improving the ability to have the right product in the right place at the right time. Wal-Mart's RFID strategy manager, Simon Langford, noted that Wal-Mart has visibility today, but it is quite fragmented. He believes that RFID is all about total supply chain visibility [7]. Real-time information can be obtained through smart shelves, which have inbuilt RFID tag receivers. This would help retailers track the exact number of products they hold.

\subsection{Asset Tracking and Returnable Items}

A recent Aberdeen Group survey of 200 companies found that more than half of the companies with RFID systems were using the technology in asset tracking [8]. RFID is ideal for identifying items that require routine calibration, inspections, or that need to be checked in or out [Participant 2]. Another advantage of using RFID technology to track assets such as tools is that the tags are virtually undetectable [Participant 2]. RFID can also track an asset's movement, use, and placement, helping to improve asset utilization [Participant 1]. Shipping companies find it difficult to track containers as they are continually transported around the world. RFID can help shipping and logistics organizations accurately track such valuable assets. In addition, RFID systems can log a container's history; if a container has been used for the delivery of dangerous items such as chemicals, RFID tracking can be used to ensure that government requirements and regulations are adhered to. Many products require special reusable containers or packaging for transportation purposes as they move along the supply chain. Objects such as beer kegs can be expensive to produce and difficult to track. TrenStar has successfully developed a system using RFID technology to manage beer kegs as they move throughout the supply chain. The new system means that TrenStar has comprehensive information on where the carts have been sent and can query retailers who have not returned them [8].

\section{The Need for Accuracy}

\subsection{Item Level Tracking}

Intermec predict that once item-level tracking is achieved, "physical inventories and product re-ordering will be done in a fraction of the time it now takes and retailers will be able to take inventory [counts] much more frequently" [9]. Item-level tracking opens the door to a whole range of potential benefits, for example theft detection or customized manufacturing [Participant 2]. Smart shelves can be described as 
shelves that have inbuilt RFID scanners allowing them to automatically monitor stock. For smart shelves to realize their maximum potential, item-level tracking is a necessity. It will allow management systems to identify and store individual product properties such as expiry dates. However, item-level tracking for perishable items such as apples and oranges, that do not require any packaging, is a separate problem altogether. According to Wal-Mart, fully automated item-level tracking for all products is inevitable, though applications like automatic checkouts are not likely to be introduced for around 10-15 years [7]. In the near future, most organizations have decided to focus on pallet and case level tracking [Participant 1].

\subsection{Traceable Warranties and Product Recalls}

Product recalls can be attributed as a costly source of loss in the supply chain. This is often because it is extremely difficult for organizations to "pinpoint only the specific faulty instances of a product [which] often leads to the destruction of perfectly good products" [10]. The level of information included on a units packaging can be the difference between making a mass recall, requiring extensive advertising and large quantities of possibly non-faulty product being recalled, or a highly specific and personalized tracking of customers who have purchased the faulty products. RFID and the Electronic Product Code (EPC) can uniquely identify every individual item in the supply chain, allowing manufacturers to obtain instant access to information that allows them to issue targeted recalls of only affected products. Subsequently, suppliers can maintain a strong and trusted brand name. Tagged items that require repair and are covered by a warranty can be authenticated, ensuring that the warranty period of the product has not expired. The item can also be monitored as the product moves back up the supply chain to the manufacturer or authorized repairer, allowing customers to receive detailed information on where their item is in the process.

\subsection{Reliability}

The reliability of RFID tags is an issue that could determine the technology's ultimate success. A multitude of pilot tests already have been carried out under a variety of operating environments. Airports are testing the technology to help track baggage and supplies, while manufacturers are using the technology to manage incoming and outgoing inventory. While some RFID tags are currently not achieving satisfactory read rates, there are numerous applications wherein
RFID is performing at a high reliability with accurate read rates. The RFID community has devoted a large amount of research to airport baggage tracking trials. After performing numerous trials and modifying their RFID system, San Francisco International Airport has been able to reach read rates consistently above $99.5 \%$ in a production environment [11]. Despite many promising applications, John Brand, a consultant from Meta Group, notes that tags are still not $100 \%$ reliable with anything from $3-5 \%$ error rates.

\section{Tag and Data Characteristics}

\subsection{Quality Control and Regulation}

RFID empowers organizations to monitor the quality of products not only internally within their manufacturing process, but also as their goods move along the supply chain. The technology permits the collection of real-time information in the manufacturing process for quality control purposes, lowering the chance of customers receiving poor quality products as well as reducing the time spent monitoring and reworking orders. Tags can monitor things like temperatures, bacteria levels and provide tamper evidence, regardless of the product position in the supply chain. This is an important capability in modern supply chains where many products are shipped around the world, exposing them to countless environmental stresses, all of which could hamper the quality of the finished good. Smart semi-active or active RFID tags can monitor these environmental forces and can automatically detect events without necessitating the inspection of every single product. For example, the U.S. army is piloting the use of RFID tags with "battery-powered sensors that can monitor temperatures in the areas where goods are shipped and stored" [12].The tags are being placed with food sent to troops in the field and are designed to ensure that food is used before the shelf life is exceeded. The RFID technology ensures troops receive food fit for consumption. RFID tags used within the EPC Network can also reduce the incidence and negate the impact of counterfeiting.

\subsection{Yard, Warehouse \& Factory Management}

In today's operating environment, it is important that business achieve the maximum productivity available from their assets. Organizations often have large levels of capital tied up in yards and factories and as such, they need to be managed efficiently. It is often difficult for these organizations to know what goods 
are on which truck without first unloading the truck, which also makes it complicated to direct the truck to the right drop off or parking yard location. RFID tags can be placed on truck trailers and RFID readers placed at entry and exit points of yards allowing management systems to log the incoming and outgoing data in realtime. The incoming truck driver can then be directed to the most efficient drop-off location. Items are unloaded faster with the yard being managed in the most resourceful manner, maximizing an organization's utilization of the asset and order fulfillment capabilities. The same principle applies to forklift drivers at warehouses. Amcor Fibre Packaging successfully uses RFID to manage its warehouse [13]. Before the warehouse management system (WMS) was implemented, their warehouse would often reach 2500 pallets, 500 more than what the warehouse was designed for, requiring production to be stopped. In addition to this, there would be between 15 and 25 trucks waiting to be loaded. The new RFID capable WMS has reduced the typical number of pallets in the warehouse to 800 with no more than 2 to 5 trucks waiting. Since the systems inception, production has not been stopped.

\subsection{Improved Inventory Management}

Manufacturers persistently struggle to get the right products to the right retailers at the right time. RFID can help solve this problem while reducing inventory levels and lowering distribution and handling costs by providing accurate and real-time information on inventory quantities and movement. The technology promises to transform the way organizations currently "forecast demand, manage inventory and distribution, and market to consumers within the store" [14]. Item level tracking is pivotal to effective inventory management. Smart-shelves would allow exact inventory stock takes to be carried out instantaneously, thanks to RFID's non-line-of-sight property. It can relay "data about location, design and history" [14]. This can help companies avoid out-of-stock situations. With research revealing that out-of-stocks can be as high as $17 \%$ for some fast-moving items, the prevention of these occurrences is important. ${ }^{15}$ RFID can enhance inventory management in a number of ways, for example, RFID systems can improve the ability to forecast product demands by $10-20 \%$ when compared to traditional systems. In addition to this, RFID systems could help lower inventory levels by $10-$ $30 \%$ and increase sales by $1-2 \%$ through reduced occurrences of out-of-stock scenarios [6].

\subsection{Security}

RFID tags are virtually impossible to copy, making them suitable to security applications. With the cost of goods 'lost' within the supply chain estimated to cost European companies 50 million euros a day, securing SCM with RFID technology is paramount [16]. It is estimated that airlines will "have to spend about $\$ 5$ billion over the next 10 years to upgrade baggage screening systems to comply with laws passed after 9/11" [17]. Theft that occurs in the supply chain is referred to as product shrinkage. Product shrinkage is rampant, with up to US\$30 billion being lost each year, the majority from the middle of the supply chain. The EPC Network allows products to be monitored, alerting SCM systems with specific details in real-time when products go missing, allowing the organization to take anti-theft measures in future occurrences. RFID can also provide theft prevention in retail outlets and distribution centers. For example, numerous uniforms were being stolen from Star City Casino, so officials placed RFID tags inside employee uniforms to prevent such theft.

\subsection{Ability to Withstand Harsh Environments}

"When environmental issues come in to play, RFID will be a godsend to read" [Participant 1]. RFID tags are extremely durable and can be read through almost all non-metallic materials. Tags can continue to work flawlessly in harsh conditions, whether the temperature is minus 40 degrees or plus 200 degrees centigrade, and will also survive in most acids [18]. This means that tags can be inbuilt into objects such as wire baskets that can travel through any number of environments. The durability of RFID tags makes them ideal for "dirty, oily, wet, or harsh industrial and commercial environments" [19]. The technology can last for extensive periods, often longer than the items they are attached to. Chrysler had attempted using barcodes in its vehicle assembly process, with limited success due to the environmental demands. However, as tags can survive very high temperatures their use is now common within the automotive industry. This means that manufacturers can continue to track vehicles regardless the demands of the manufacturing process.

\subsection{Information Properties}

The data capacity of RFID tags permits them to vary in size, from holding only a few bits to thousands of bits. Tags can have the capacity to store and handle the needs and wants of most users. This data capacity is 
what makes the identification of individual products feasible. Tags can hold vast quantities of information, ranging from “an item's serial number, color, size, manufacture data and current price as well as a list of all distribution points the item touched before arriving at a store" [9]. In addition to this, tags can be updated dynamically, storing new information from RFID readers as they move across the supply chain.

\section{Cost Considerations}

\subsection{Cost Savings}

Cost savings through RIFD systems are derived through many of the areas already discussed in this paper, namely labor reduction, enhanced inventory management, advanced security and more efficient management of assets. Through deploying RFID domestically, it is estimated that the U.S. economy stands to save over US\$500 billion annually, solely through RFID's superior inventory management capabilities [17]. European companies are set to reap billions of dollars in savings upon RFID's wide acceptance, just through reduced inventory levels [16]. While the anticipated total savings expected from RFID range significantly, most reports predict that there will be considerable savings. AMR has estimated that Wal-Mart's supply chain costs are in the vicinity of $10 \%$ of all sales. AMR expects Wal-Mart to realize a saving of around 6-7\% of supply chain costs through the use of RFID, equating to around US\$1.4 billion [20].

\subsection{Software and Equipment Upgrades}

The integration of RFID into existing practices requires considerable investment from organizations [Participant 1]; reengineering the business and aligning the systems takes time. The process of implementing the technology will affect all facets of the organization, with the entire process expected to cost millions of dollars. Wal-Mart has come under fire from many of its suppliers, as it is believed that the cost of compliance with the retailer's mandate will reach US\$9 million [7]. Gartner has indicated that companies should allow a five-year period and US\$20 million to integrate RFID technology into current processes [21]. Some parties are concerned that there is a skills shortage in the RFID industry as well, which will become apparent when the number of firms installing RFID equipment increases. Capital outlays required by RFID are likely to deter the cash strapped airline industry from using the technology in their baggage handling systems. Many airline networks span a large number of airports generating significant financial implications.

\subsection{Cost of Technology}

Presently, RFID technology is expensive and the price of RFID tags has traditionally been a significant obstacle to its widespread deployment in SCM. An Accenture survey found cost to be one of the two primary barriers to the implementation of RFID [22]. Reports on the current cost of RFID tags vary, however they all find common ground in noting that the current cost of tags is too high to justify tagging all items. This is why most companies mandating the use of RFID are focusing on tagging pallets and cases, as opposed to item-level tracking, which is years away. Current passive tag cost estimates range from US\$0.15 to US\$0.75, with the volume of tags purchased having a significant impact on the cost.

\section{Deployment Issues}

\subsection{Manufacturing Sector Concerns}

A large portion of the push for RFID uptake is coming from retailers who are forcing manufacturers to absorb the additional costs associated with tagging items and processing the information they generate. Many consumer goods manufacturers are struggling to see any short-term gain from upgrading to RFID technology on their packaging and distribution systems. Consequently, it is being viewed as the cost of doing business with major customers such as Wal-Mart, Target, Albertsons and the U.S. Department of Defense, which have mandated that suppliers phase in the use of RFID from 2005. Some manufacturers are investigating the 'slap and ship' option where they keep their current processes in place. This involves only tagging items as they are shipped, in an effort to minimize costs and meet mandated requirements. However, even such minimal approaches can cause problems such as errors with the placement and engineering of tags that need to be readable by customers [8]. Clearly, organizations lack standards for integrating RFID into their daily practices.

\subsection{Supplier and Retailer Cooperation}

RFID tags using the EPC standard only contain a serial number. Databases linking these serial numbers to further information are then required to make use of this information. "Data synchronization, integration, transformation, and communication are huge barriers in 
making the technology work for organizations".23 Previous endeavours to collaborate across organizations have been unsuccessful as information could not be readily extracted and shared. All parties are required to collaborate with one another to decipher specifically what information they need and how it should be disseminated.

\subsection{Lack of Standards}

While RFID technology has been around for decades, it has only been recently that its uptake in SCM has been touted. As a result, there is an apparent lack of standards hindering the technology's adoption and support for widespread use in supply chains. Participant 1 noted that as past RFID products did not possess interoperable qualities, they could not be easily integrated into the supply chain between partners and as such they did not add value. The development of standards has progressed somewhat through the formation of the EPCglobal network, a member based organization comprised of numerous large firms funding its operations. However, EPCglobal's standard is yet to be backed by the International Organization for Standardization (ISO). There is still no standard supported by all stakeholders that meets the needs of all users. Incompatible systems exist across different industries, from rail, truck, toll collection, retail and manufacturing. Hence, interoperability is a foremost concern for the seamless use of RFID across supply chains. The EPC standard is of paramount importance to the success of RFID. Ongoing refinements and the backing of numerous multinational organizations mean that it will most likely become the adopted standard in SCM [Participant 1]. Another perplexing issue is radio spectrum allocation. Radio spectrum is a finite resource and although numerous institutions try to ensure spectrum management, it is ultimately in the control of government agencies in different countries.

\subsection{Interference and Reading Considerations}

As RFID uses the radio spectrum to transmit its signals, it is susceptible to interference, hindering its ability to transmit clear and reliable information to RFID readers [Participant 1]. Similarly, RFID suffers from the inherent range limitations associated with the radio spectrum. Tagging is also not simply a matter of attaching RFID tags to items. Readers are only able to read tags that are facing a particular way, so items need to be packed accordingly [Participant 1]. Another problem arises when a pallet containing different packaged items is read, as the reader needs to be aware it is reading multiple types of items. However, RFID's ability to read through most packaging material such as plastic wraps and cardboard containers is one of its most valuable assets. Metal and liquid have been described as the "kryptonite to RFID" as they can play havoc with RFID signals [23]. Determining the best position for RFID tags can be time consuming, with one company testing six areas on a liquid product, with only one or two of those giving a best read [8]. Procter \& Gamble created "RF-friendly" and "RF-unfriendly" product categories, with those containing some form of metal packaging or liquid often making the RFunfriendly category [24].

\subsection{Privacy Concerns}

Privacy issues loom as one of the biggest threats to the unbridled success of RFID. Privacy concerns have the potential to "stop a technology dead in its tracks" [23]. Current RFID protocols are designed to offer the most optimal performance between readers and tags, neglecting to address consumer privacy concerns. Privacy advocates are worried that if RFID tags are placed in common items, the product may continue to be tracked once purchased by consumers [25]. Human rights organizations have already raised their disquiet over the technology. In an effort to counter privacy concerns, the Auto-ID Center has published a paper outlining three fundamental privacy policies for all users of EPC technology [26]. Clothing retailer Benetton came under fire for placing RFID tags in its clothes. Once the public was made aware of this, consumers called for a boycott against Benetton, causing the retailer to abandon its RFID plans. One of the public's biggest concerns with the plan was that there was a lack of information about how the tags could be 'turned off' once an item was purchased [27].

\section{Conclusion}

The results of this paper are relevant to all organizations concerned with optimizing their supply chain through the adoption of RFID. Recently, a number of the world's largest retailers and government agencies such as Wal-Mart and the U.S. Department of Defense introduced mandates for RFID adoption. As the use of RFID for SCM is relatively new and undocumented with only a limited number of RFID deployments, many businesses are unsure what they stand to gain. Compounding this issue is the fact that most large organizations have already invested heavily in barcode systems and are skeptical about RFID technology. This paper provided an extensive 
investigation into the pros and cons of RFID technology within an SCM context, giving businesses the opportunity to weigh up the costs and benefits.

\section{References}

[1] CSX World Terminals, "LLC", [Online] <URL: http://www.csxworldterminals.com/Resources/Glossary .asp?s=s> Last accessed, 11/3/2004 (2001).

[2] Softchain, Improving Extended Supply Chain Performance Through Better Control, [Online] <URL:http://www.manufacturing.net/scm/contents/pdf/ softchain_wp.pdf> Last accessed, 1/3/2004 (2002).

[3] Keith, A. et. al., Focus on the Supply Chain: Applying Auto-ID within the Distribution Center, IBM Business Consulting Services, Auto-ID Center, Massachusetts Institute of Technology, 2002.

[4] Mills, K., "Tags Weigh in for Landfill Trucks", The Australian, 2004, p. 3.

[5] Teresko, J., "Winning with Wireless". Industry Week, 252(6), [Online] Available ProQuest, Last accessed, 12/10/2004 (2003).

[6] Zebra Technologies, Zebra's RFID Readiness Guide: Complying with RFID Tagging Mandates, p. 3.

[7] Donoghue, A., "RFID: Proceed with Caution", ZDNet, [Online] <URL:http://www.zdnet.com.au/ insight/hardware/0,39023759,39147123,00.htm> Last accessed, 27/9/2004.

[8] Albright, B., "RFID Tag Placement", [Online] <URL: http://www.frontlinetoday.com/frontline/article/ articleDetail.jsp?id=98552 $>$ Last accessed, 7/9/2004.

[9] Intermec Technologies, "RFID Technology In Retail", 2002, p. 3.

[10] VeriSign, "The EPC Network: Enhancing the Supply Chain," [Online] <URL:http://www.verisign. com/nds/directory/epc/epc_whitepaper.pdf> Last accessed, 1/3/2004, 2002, p. 4.

[11] Foster, P., "San Francisco Airports RFID Baggage Handling System", Aviation Security Manager, San Francisco International Airport, 2004.

[12] Brewin, B., "Army to Test Passive RFID Tags on Food Shipments", Computerworld, <URL:http://www. computerworld.com/softwaretopics/erp/story/0,10801,8 7623,00.html > Last accessed, 24/10/2004 (2003).

[13] Wind, G., "Creating Business Intelligence from What Were Black Holes of Information and Data", R.F.I.D. World, Sydney, 2004.

[14] IBM Business Consulting Services, "Streamlining the Supply Chain Using Radio Frequency Identification", [Online] <URL:http://www-1.ibm.com/ services/us/bcs/pdf/g510-3839-treamlining-supply- chain-using-radio-frequency-identification.pdf $>$ Last accessed, 27/9/2004, pp. 2, 5.

[15] Roberti, M., "Analysis: RFID- Wal-Mart's Network Effect", [Online] <URL:http://www. cioinsight.com/print_article/0,1406,a=61672,00.asp>

Last accessed, 24/7/2004 (2003).

[16] Atock, C., "Where's My Stuff?" Manufacturing Engineer, April, 2003, p. 23.

[17] Chandrashekhar, M., "It Fits the Bill!" Businessline, [Online], Available ProQuest, Document Id: 623937701. Last accessed, 10/10/2004.

[18] D'Hont, S., "The Cutting Edge of RFID Technology and Applications for Manufacturing and Distribution", Texas Instrument, [Online] <URL:http://www.ti.com/tiris/docs/manuals/whtPapers/ manuf_dist.pdf $>$ Last accessed, 27/8/2004.

[19] Motorola, Inc., "Electro-Magnetic RFID: Everything You Need to Know About Inductively Coupled RFID”, 1997, p. 1.

[20] Shim, R., "Wal-Mart to Throw its Weight Behind RFID", CNET News [Online] <URL:http://news.com. com/2102-1022_3-1013767.html> Last accessed, 26/8/2004 (2003).

[21] Frontline Solutions, "Return of RFID Investment will Require Creativity", [Online] <URL: http://www. frontlinetoday.com/frontline/article/articleDetail.jsp?id $=125499>$ Last accessed, 2/10/2004.

[22] Accenture, "High-Performance Enabled through Radio Frequency Identification", [Online] <URL:http://www.accenture.com/xdoc/en/services/rfid/ capabilities/rfid_maximize.pdf $>$ Last accessed, 28/9/2004.

[23] McGinity, M., “RFID: Not Your Father's Bar Code", IEEE Distributed Systems Online, [Online] <URL:http://dsonline.computer.org/0308/f/newsp.htm> Last accessed, 9/9/2004.

[24] Brewin, B., "Consumer Packaged Goods Firms: No Quick ROI from RFID", Computerworld [Online] <URL:http://www.computerworld.com/printthis/2004/0 ,4814,91797,00.html> Last accessed, 26/9/2004.

[25] Want, R., "Enabling Ubiquitous Sensing with RFID”, Invisible Computing, April, [Online] <URL:http://www.computer.org/computer/homepage/0 404/invisible/r4084.pdf> Last accessed, 8/9/2004, p. 84.

[26] Roberti, M., "RFID: Mark Benneton on Privacy Woes", [Online] <URL:http://www.cioinsight.com/ print_article/0,1406,a=61672,00.asp $>$ Last accessed. 24/7/2004 (2003).

[27] Sanford, V., "Pervasive Computing Goes the Last Hundred Feet with RFID Systems", IEEE CS and IEEE ComSoc, April-June, 2003. 